\title{
Unexplained Syncope and Diagnostic Yield of Tests in Syncope According to the ICD-10 Discharge Diagnosis
}

\author{
Martin Huth Ruwald ${ }^{\mathrm{a}, \mathrm{c}}$, Morten Lock Hansen ${ }^{\mathrm{a}, \mathrm{b}}$, Morten Lamberts ${ }^{\mathrm{a}}$, Michael Vinther ${ }^{\mathrm{a}}$, \\ Christian Torp-Pedersen ${ }^{\mathrm{a}}$, Jim Hansen ${ }^{\mathrm{a}}$, Gunnar Hilmar Gislason ${ }^{\mathrm{a}}$
}

\begin{abstract}
Background: The etiology of syncope according to the discharge diagnosis from hospital admissions has not been examined before. Therefore the aims of this study were to examine the diagnostic yield of tests and frequency of unexplained cases during admission and after workup after an ICD-10 diagnosis of syncope.
\end{abstract}

Methods: A retrospective chart review of 600 patients discharged with the primary ICD-10 discharge diagnosis of syncope R55.9 was performed. Causes and clinical characteristics of syncope according to the physician were noted both after initial discharge and after workup.

Results: During a mean follow-up period of 2.5 years (SD: \pm 1.30 ) several diagnostic tests were used (mean number of tests per patient was 4.7 (SD: \pm-2.0$)$ ) and the mean length of admission was 2.1 days $( \pm 1.5)$. The final diagnosis after workup was reflex syncope in $21 \%$, cardiac $18 \%$, orthostatic hypotension $10 \%$, other causes $4 \%$ and unknown/unexplained syncope in $48 \%$ with wide age differences. The diagnostic yield of tests was generally low and differed widely depending on usage during admission or usage during subsequent workup.

Conclusions: The underlying etiology of syncope remains difficult to establish despite the high use of diagnostic tests and the diagnostic yield of many tests implemented in the care path is generally low.

Keywords: Syncope; Diagnostic techniques; Cardiovascular; Etiology

\footnotetext{
Manuscript accepted for publication August 23, 2013

${ }^{\text {a } D e p a r t m e n t ~ o f ~ C a r d i o l o g y, ~ G e n t o f t e ~ H o s p i t a l, ~ D e n m a r k ~}$

${ }^{\mathrm{b}}$ Department of Cardiology, Herlev Hospital, Denmark

${ }^{\mathrm{c}}$ Corresponding author: Martin Huth Ruwald, Department of

Cardiology, Gentofte Hospital, Denmark.

Email:mruwald@hotmail.com

doi: http://dx.doi.org/10.4021/jocmr1569w
}

\section{Introduction}

Syncope is a common condition associated with frequent hospitalizations [1-4] that is difficult to evaluate and is associated with a high mortality rate in selected subgroups of patients [5-10]. Existing patterns of care are characterized by high diversity, high cost and low diagnostic and therapeutic yield. Between $39 \%$ and $50 \%$ of admitted patients are discharged without an explanation for syncope [11], and in one study $60 \%$ of older patients received no specific therapies during their admission [8]. Etiologic explanation of syncope is important to implement correct therapeutic strategies and for risk stratification. In most patients with syncope, the initial evaluation does not provide a definite diagnosis and additional diagnostic testing is often needed. The strategy for testing is usually clearer when syncope occurs in the presence of severe structural heart disease. However, in the elderly and in patients with suspected, but undiagnosed arrhythmias or vasovagal syncope, elucidation is required for the role of long term ECG recording, implantable loop recorders, tilttable tests and carotid-sinus massage. The challenge is to reduce the number of patients where syncope remains unexplained. The primary objective of this retrospective study was to explore which etiologic category syncope could be assigned to after discharge and after workup and to estimate the use of diagnostic tests and the diagnostic yield. We hypothesized that, in a contemporary clinical setting, the etiology of syncope after discharge would be difficult to establish even with the use of a wide range of tests.

\section{Materials and Methods}

\section{Study population}

We retrospectively identified a cohort of patients who weredischarged for syncope according to the discharge diagnosis R55.9 ('syncope and collapse') from January 1st, 2007 to December 31, 2010 on three University hospitals in the Capital Region of Copenhagen.

A total of 1,223 charts of discharged patient for syncope 
Table 1. Baseline Characteristics

\begin{tabular}{|c|c|}
\hline Characteristics & Total (\%) \\
\hline Number of patients & $570(100)$ \\
\hline Men & $297(52)$ \\
\hline Age years (IQR) & $68.5(53-81)$ \\
\hline Previous syncope & $130(23)$ \\
\hline Prodromal symptoms & $249(44)$ \\
\hline \multicolumn{2}{|l|}{ Comorbidities } \\
\hline Ischemic heart disease & $126(22)$ \\
\hline Peripheral vascular disease & $78(14)$ \\
\hline Previous myocardial infarction & $87(15)$ \\
\hline Systemic hypertension & $288(51)$ \\
\hline Previous or current atrial fibrillation & $77(14)$ \\
\hline Other arrhythmias & $37(6)$ \\
\hline Previous stroke & $72(13)$ \\
\hline Congestive heart failure & $61(11)$ \\
\hline Previous or ongoing cancer & $49(9)$ \\
\hline Chronic obstructive pulmonary disorder & $46(8)$ \\
\hline Diabetes & $56(10)$ \\
\hline Cardiac pacemaker or ICD unit & $21(4)$ \\
\hline Epilepsy & $7(1)$ \\
\hline Alcoholism & $18(3)$ \\
\hline Dementia & $29(5)$ \\
\hline Depression & $25(4)$ \\
\hline Previous PCI or CABG & $61(11)$ \\
\hline Previous or current smoker & $223(39)$ \\
\hline Alcohol intake above recommended level & $124(22)$ \\
\hline \multicolumn{2}{|l|}{ Pharmacotherapy } \\
\hline Beta blockers & $140(25)$ \\
\hline ACEi/ARB & $210(37)$ \\
\hline Digoxin & $21(4)$ \\
\hline Nitrates & $34(6)$ \\
\hline Calcium channel blockers & $85(15)$ \\
\hline Spironolactone & $21(4)$ \\
\hline Thiazide & $111(19)$ \\
\hline Loop diuretics & $85(15)$ \\
\hline Class Ic antiarrhythmic drugs & $1(0)$ \\
\hline Class III antiarrhythmic drugs & $13(2)$ \\
\hline Anxiolytics & $56(10)$ \\
\hline Antipsychotics & $27(5)$ \\
\hline Antidepressants & $76(13)$ \\
\hline Glucose lowering drugs & $51(9)$ \\
\hline
\end{tabular}

Age is given in median and interquartile range (IQR). ACEi: angiotensin converting enzyme inhibitor; ARB: angiotensin receptor blocker; PCI: percutaneous coronary intervention; CABG: coronary artery bypass graft. 
Table 2. The Total Number of Tests Used During First Admission and Workup

\begin{tabular}{llll}
\hline Test & Number (\%) & Abnormal test (\%) & $\begin{array}{l}\text { Definite diagnosis } \\
\text { Diagnostic yield of test (\%) }\end{array}$ \\
\hline Total tests & 2601 & $632(24)$ & $165(6)$ \\
Laboratory and blood results & $570(100)$ & NA & NA \\
ECG & $569(100)$ & $235(41)$ & $22(4)$ \\
Telemetry & $431(76)$ & $103(24)$ & $18(4)$ \\
Echocardiogram & $272(48)$ & $97(36)$ & $11(4)$ \\
Long-term ECG monitoring & $198(35)$ & $70(35)$ & $29(15)$ \\
Stress ECG & $43(8)$ & $6(14)$ & $2(5)$ \\
Orthostatic hypotension test & $114(20)$ & $31(27)$ & $23(20)$ \\
Electrophysiological study & $29(5)$ & $3(10)$ & $3(10)$ \\
Tilt table & $60(11)$ & $34(57)$ & $28(47)$ \\
Carotid sinus massage & $61(11)$ & $5(8)$ & $5(8)$ \\
Implantable loop recorder & $38(7)$ & $7(18)$ & $7(18)$ \\
MRI cerebrum & $25(4)$ & $6(24)$ & $3(12)^{*}$ \\
CT cerebrum & $143(25)$ & $25(17)$ & $4(3)^{*}$ \\
Electroencephalogram & $48(8)$ & $10(21)$ & $10(21)^{*}$ \\
\hline
\end{tabular}

ECG: electrocardiogram; MRI: magnetic resonance imaging; EP: electrophysiological; CT: computed tomography. ${ }^{*}$ These 17 patients were all diagnosed with neurological disease during the workup, primarily epilepsy, thus the diagnostic yield was as counted, but the patients were probably ultimately classified wrongly as syncopal origin.

were identified through the electronic patient management system, 23 charts were insufficient for documentation or the chart could not be accessed by the reviewers. From this overall syncope population of 1,200 , we randomly selected $50 \%$ (due to resources) from each hospital of the total discharged patients for individual chart review. Of these 600 patients, 570 (95\%) satisfied the European Society of Cardiology (ESC) definition of total loss of consciousness and syncope [12] and entered the analysis and baseline model. We have previously validated the R55.9 discharge diagnosis code in the same cohort and in 5,262 other medical patients and found a positive predictive value of $95 \%$ and a sensitivity of $63 \%[13]$.

All charts from discharged patients were read independently, reviewing all notes from the physician history and physical examination, physician notes during rounds and at discharge, imaging reports (if available), laboratory tests, electrocardiogram (ECG) or echocardiography reports, and any other pertinent investigations (for example, tilt-testing, electrophysiological studies, orthostatic hypotension test or carotid sinus massage). The most likely cause of the syncope according to the discharging physician was noted both after initial admission and after workup.
The workup of each individual patient was reviewed during December 2011 by examining the patient charts from the date of the initial syncope, which had the discharge diagnosis of R55.9 in the study period. The etiology was determined and noted if definite diagnosis was made within the study period otherwise the syncope had to be classified as unknown.

\section{Hospitals chosen for chart review}

Of the three hospitals, one is a major center of cardiology with a specialized syncope unit and catheter laboratory for pacemaker implantations, coronary angiography and cardiac ablations, while the other two are representative of large volume hospitals with large open-referral emergency departments and designated departments of internal medicine and neurology.

\section{Statistics}

Patient demographics (age, sex, pharmacotherapy and comorbidity) were analyzed for all patients identified as having syncope based on the administrative coding in the database. 
Table 3. Number of Tests Performed During First Admission in the 207 (35\%) Patients Where the Etiological Diagnosis was Made During Admission

\begin{tabular}{llll}
\hline Test & Number (\%) & Abnormal test (\%) & $\begin{array}{l}\text { Definite diagnosis. } \\
\text { Diagnostic yield of test during } \\
\text { admission (\%) }\end{array}$ \\
\hline Laboratory and blood results & $207(100)$ & NA & NA \\
ECG & $207(100)$ & $83(40)$ & $17(8)$ \\
Telemetry & $144(70)$ & $44(31)$ & $16(11)$ \\
Echocardiogram & $72(35)$ & $33(46)$ & $7(10)$ \\
Stress ECG & $7(3)$ & $1(14)$ & $1(14)$ \\
Orthostatic hypotension test & $32(16)$ & $20(63)$ & $15(47)$ \\
Electrophysiological study & $5(2)$ & $1(20)$ & $1(20)$ \\
Carotid sinus massage & $10(5)$ & $2(20)$ & $2(20)$ \\
CT cerebrum & $29(14)$ & $9(31)$ & $3(10)^{*}$ \\
\hline
\end{tabular}

*These 3 patients received another definitive diagnosis than syncope and were ultimately classified wrongly by the physician.

Age, distributed in a non-Gaussian fashion, was expressed as median and interquartile ranges. T-test and non-parametric Mann-Whitney U test were used where appropriate on variables. Comparison between proportions and groups was by means of the chi square test. For patients included in the chart review, information collected on the abstraction form regarding diagnostic and treatment procedures was reported descriptively.

All data management and analyses were conducted using SAS Version 9.2 (SAS Institute, Inc., Cary, NC), and findings with two-sided P-values $<0.05$ were considered statistically significant.

Table 4. Number of Tests Performed During Workup in 102 Patients Where the Etiological Diagnosis Was Unknown at Discharge but Apparent After Workup

\begin{tabular}{llll}
\hline Test & Number (\%) & Abnormal test (\%) & $\begin{array}{l}\text { Definite diagnosis. } \\
\text { Diagnostic yield of test (\%) }\end{array}$ \\
\hline Echocardiogram & $74(73)$ & $25(34)$ & $5(7)$ \\
Long-term ECG monitoring & $72(71)$ & $32(44)$ & $19(26)$ \\
Stress ECG & $13(13)$ & $1(8)$ & $1(8)$ \\
Orthostatic hypotension test & $30(29)$ & $8(27)$ & $7(23)$ \\
Electrophysiological study & $10(10)$ & $2(20)$ & $2(20)$ \\
Tilt table & $36(35)$ & $25(69)$ & $22(61)$ \\
Carotid sinus massage & $36(35)$ & $3(8)$ & $3(8)$ \\
Implantable loop recorder & $12(12)$ & $6(50)$ & $6(50)$ \\
MRI cerebrum & $10(10)$ & $4(40)$ & $3(75)^{*}$ \\
CT cerebrum & $26(25)$ & $5(19)$ & $4(15)^{*}$ \\
Electroencephalogram & $13(13)$ & $4(31)$ & $4(31)^{*}$ \\
\hline
\end{tabular}

*These 11 tests were performed in patients who received another definitive diagnosis than syncope and were initially classified wrongly by the discharging physician. 


\section{Ethics}

The study was approved by the Danish Data Protection Agency (ref. 2007-58-0015, int. ref: GEH-2010-001).

\section{Results}

A total of 600 charts from patients discharged after syncope (ICD-10 diagnosis. R559) were reviewed systematically of which 570 (95\%) satisfied the ESC criteria for syncope [12]. The median age was 68.5 years (IQR 53 - 81), and 48\% were female. The mean follow-up period was 2.5 years $(\mathrm{SD} \pm$ $1.30)$ and the mean length of admission of 2.1 days $( \pm 1.5)$. A history of hypertension was present in $51 \%$, ischemic heart disease in $22 \%$, atrial fibrillation in $14 \%$, congestive heart failure in $11 \%$ and diabetes in $10 \%$. No major differences between the three hospitals were seen in terms of comorbidities or pharmacotherapy and the patient baseline characteristics of comorbidities and pharmacotherapy are presented in Table 1. Of the 570 patients, 249 (44\%) presented with prodromal symptoms, primarily represented by "light-headedness", nausea and sweating accounting for $61 \%$, whereas palpitations, chest pain and exertion accounted for $6 \%, 4 \%$ and $6 \%$, respectively.

\section{Diagnostic tests}

The diagnostic tests used during admission and workup consisted of a wide variety of diagnostic tests, mostly used was ECG (100\%), laboratory tests (100\%), telemetry (76\%), echocardiogram (48\%) and long-term ECG monitoring $(35 \%)$ as listed in Table 2. The diagnostic overall yield of tilt-testing was found to be $47 \%, 20 \%$ using the orthostatic hypotension test and $18 \%$ using implantable cardiac monitoring while resting ECG and echocardiogram yielded a diagnosis in $4 \%$ of the patients as shown in Table 2 . The mean number of tests per patient was 4.7 (SD: \pm 2.0 ).

In 207 patients $(35 \%)$ the etiological diagnosis was made during the admission. In these patients the diagnostic yield of the echocardiogram, ECG, orthostatic hypotension test and telemetry were markedly higher compared to the entire cohort (Table 3). In 102 patients (18\%) an etiological diagnosis was made during workup (initially classified as unknown). In these patients the diagnostic yield of implantable loop recorder, tilt table test and long-term ECG monitoring were markedly higher than in the total cohort (Table 4). Eleven patients who initially received a definite etiological diagnosis by the discharging physician but referred for further workup were subsequently reclassified as unknown after further workup. Comparing Table 3 and Table 4, an etiological diagnosis is much more likely to be made based on an abnormal test performed during workup than an abnormal test performed during the initial admission.

\section{Etiology}

During the course of workup $24(4 \%)$ were ultimately diagnosed with conditions mimicking syncope, primarily epilepsy (10 patients).

Table 5 shows the various etiologies of syncope after admission and after workup, respectively. Final diagnosis after workup was reflex syncope $21 \%$, cardiac cause $18 \%$ represented by severe brad arrhythmias or blocks $12 \%$, ventricular arrhythmias 3\% and other cardiac causes 3\%. Orthostatic hypotension accounted for $10 \%$, other non-syncopal causes $4 \%$ and ultimately $48 \%$ remained of unknown etiology. All accounted etiologies were significantly different comparing before and after workup. Table 5 furthermore shows the agedependent variation in etiology. When dichotomized at the age of 65 years, reflex syncope is significantly more prevalent in the younger, orthostatic and cardiac causes in the elderly while the difference in prevalence of other causes and unknown etiology remain insignificant.

At the end of diagnostic evaluation, a diagnosis of primary cardiac etiology was established in $15 \%, 26 \%$ and $15 \%$ at the three hospitals respectively (including referrals to other hospitals-data not shown).

Table 6 shows the proportions of selected comorbidities and pharmacotherapy according to the result of the diagnostic workup. High amount of cardiovascular comorbidity was noted in the group of cardiac etiology and very low rate of cardiovascular comorbidity was seen in the group of reflex syncope. Comparable rates of cardiovascular medication and comorbidity is noted in the group of unknown diagnosis and cardiac diagnosis.

Light-headedness, nausea or sweating as a predominant symptom was significantly $(\mathrm{P}<0.001)$ associated with a final etiological diagnosis of reflex syncope, while no significant association was found between cardiac etiology and chest pain or palpitations, probably due to low absolute numbers (Table 7).

\section{Discussion}

Major findings of this study were the relatively low diagnostic yield and the high number of unexplained cases. This supports previous studies in unselected cohorts, but we approached patients with syncope according to the diagnostic coding used in most countries, which is a major difference and this study should be interpreted with this fact in mind. The general evaluation of a patient with syncope involves a myriad of diagnostic tests, but the annual cost of syncope related admissions is very hard to calculate as no administrative coding is specifically designed for all syncope. It is, however, estimated that the annual costs of syncope related admissions in the US exceeds $\$ 2$ billion [14]. Some clinical risk stratification algorithms have been developed to identify 


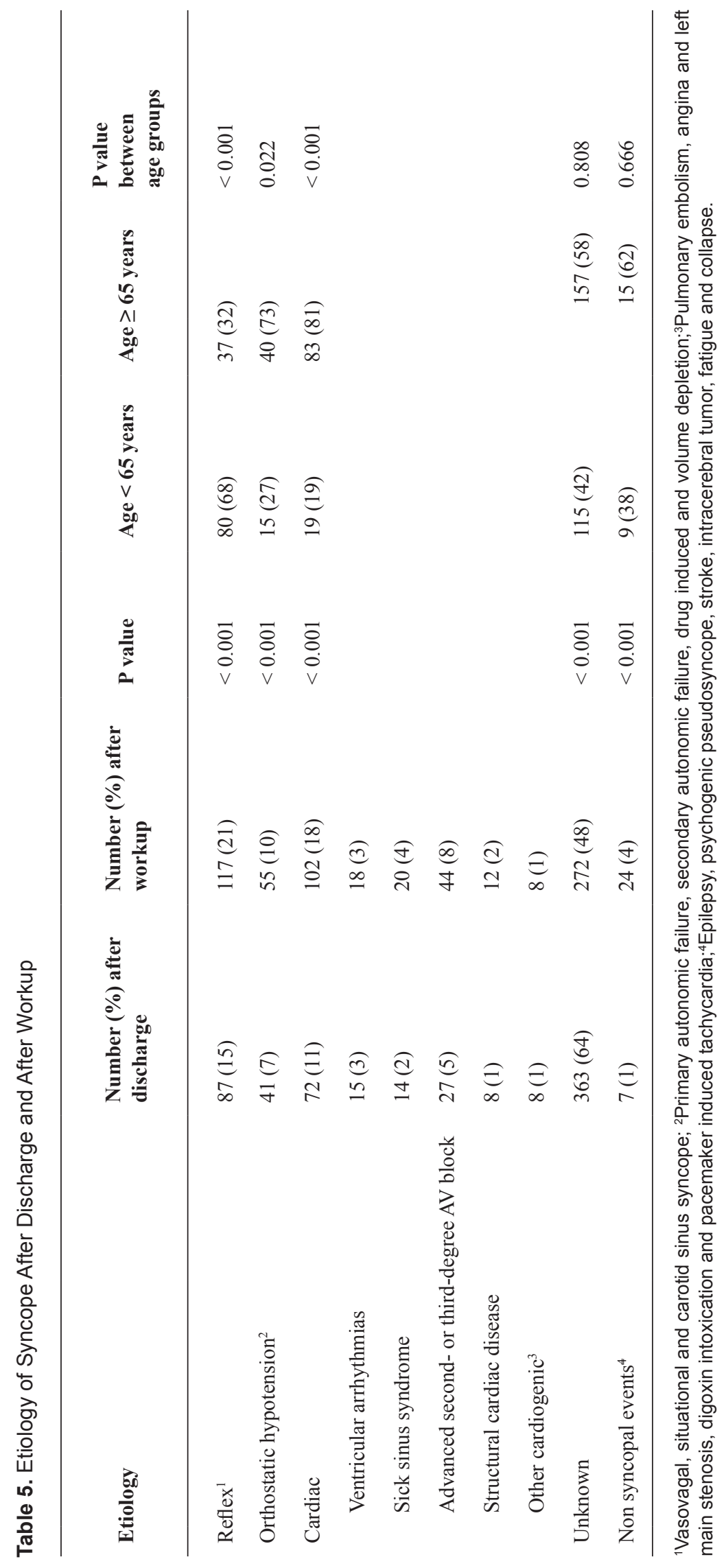


Table 6. Selected Pharmacotherapy and Comorbidity According to Diagnosis After Workup

\begin{tabular}{llllll}
\hline $\begin{array}{l}\text { Pharmacotherapy and } \\
\text { Comorbidity }\end{array}$ & $\begin{array}{l}\text { Unknown } \\
\mathbf{N = 2 7 2}\end{array}$ & $\begin{array}{l}\text { Cardiac } \\
\mathbf{N = 1 0 2}\end{array}$ & $\begin{array}{l}\text { Orthostatic } \\
\mathbf{N}=\mathbf{5 5}\end{array}$ & $\begin{array}{l}\text { Reflex } \\
\mathbf{N}=\mathbf{1 1 7}\end{array}$ & $\begin{array}{l}\text { Other causes } \\
\mathbf{N}=\mathbf{2 4}\end{array}$ \\
\hline $\begin{array}{l}\text { Comorbidity (in \%) } \\
\text { CHF }\end{array}$ & $28(10)$ & $24(23)$ & $6(11)$ & $2(2)$ & $1(4)$ \\
IHD & $67(24)$ & $39(38)$ & $11(20)$ & $6(5)$ & $5(20)$ \\
AMI & $47(17)$ & $27(28)$ & $9(16)$ & $4(3)$ & $0(0)$ \\
AF & $39(14)$ & $25(24)$ & $5(9)$ & $7(6)$ & $2(8)$ \\
Other arrhythmias & $12(4)$ & $15(14)$ & $4(7)$ & $4(3)$ & $2(8)$ \\
Stroke & $34(12)$ & $19(18)$ & $12(22)$ & $3(2)$ & $4(15)$ \\
Diabetes & $21(8)$ & $15(15)$ & $12(22)$ & $5(4)$ & $2(8)$ \\
Cardiac device & $10(4)$ & $6(6)$ & $3(5)$ & $2(2)$ & $0(0)$ \\
Depression & $12(4)$ & $6(6)$ & $6(11)$ & $1(1)$ & $0(0)$ \\
Pharmacotherapy (in \%) & & & & & \\
Beta blockers & $67(25)$ & $41(39)$ & $18(33)$ & $14(12)$ & $1(4)$ \\
ACE/ARB & $104(38)$ & $53(51)$ & $27(49)$ & $20(17)$ & $8(31)$ \\
Thiazide & $54(20)$ & $18(17)$ & $14(25)$ & $18(15)$ & $7(27)$ \\
Loop diuretics & $40(15)$ & $30(29)$ & $11(20)$ & $3(3)$ & $2(8)$ \\
Anxiolytics & $33(12)$ & $9(9)$ & $8(15)$ & $3(3)$ & $3(12)$ \\
Antipsycotics & $14(5)$ & $3(3)$ & $6(11)$ & $2(2)$ & $2(8)$ \\
Antidepressants & $43(16)$ & $(12)$ & $11(20)$ & $8(7)$ & $3(12)$ \\
\hline
\end{tabular}

CHF: congestive heart failure; IHD: ischemic heart disease; AMI: acute myocardial infarction; AF: atrial fibrillation; ACE: angiotensin converting enzyme; ARB: angiotensin receptor blocker.

the high-risk patients but none are widely implemented [1517]. On the other hand, much evidence points to the very limited utility of performing some tests, such as the basic laboratory tests, cerebral computed tomography, cerebral magnetic resonance imaging and electroencephalography, which, in these unselected patients, have a diagnostic yield of $1 \%$ or even less, if used as primary diagnostic tools [18]. The routine use is discouraged by scientific guidelines [12]. Despite this, we find in our study that they are still frequently performed, suggesting that current practice is not in concordance with current guidelines. Concordantly we found a relatively high amount of diagnostic test being used during workup of these patients. We found resting ECG and longterm ECG monitoring to have relatively low diagnostic yield as comparable to previous studies [18-20]. Important variations in diagnostic yield were evident comparing those who received definite diagnosis during admission and those who received definite diagnosis during the workup (Tables 3, 4). This relationship reflects the stepwise selection of patients, but importantly it is noteworthy that in our study the im- plantable loop recorder and tilt table test proved useful in the workup. The relatively high yield of EEG, MRI and cerebral computed tomography was only due to a definite diagnosis of neurological origin. The diagnostic yield of these tests in terms of a final etiological cause for syncope was 0 for all three tests. Ultimately only $5 \%$ received a diagnosis covered by a syncope-mimicking disease, such as epilepsy. We suggest that more syncope-mimicking conditions may reside among the large proportion on unexplained cases as proposed by others [21, 22], which could justify these tests for neurological mimics of syncope in a few selected patients. Interpretation of advanced tests and correct prioritizing of health care resources calls for multidisciplinary syncopemanagement clinics and close collaboration among medical specialties as suggested by Shen et al [23]. Such units have been advocated in order to access expertise and ensure fast diagnostics and risk stratification at lower costs [12, 24, 25].

The relatively high diagnostic yield of tilt-table test was probably due to a selection process towards healthier patients, where vasovagal syncope was the most likely cause 
Table 7. Predominant Prodromal Symptom and Final Etiological Diagnosis

\begin{tabular}{|c|c|c|c|c|c|}
\hline \multirow{2}{*}{ Predominant prodrome } & \multicolumn{5}{|c|}{ Etiology } \\
\hline & Cardiac & Orthostatic & Reflex & Unknown & P value \\
\hline Palpitations (\%) & $2(2)$ & 0 & $2(2)$ & $12(4)$ & 0.045 \\
\hline $\begin{array}{l}\text { Light-headedness, nausea and } \\
\text { sweating }(\%)\end{array}$ & $19(19)$ & $16(29)$ & $58(50)$ & $54(20)$ & $<0.001$ \\
\hline Chest pain (\%) & $1(1)$ & $3(5)$ & 0 & $5(2)$ & 0.330 \\
\hline During exercise (\%) & $3(3)$ & 0 & 0 & $9(3)$ & 0.527 \\
\hline
\end{tabular}

of the syncope and since no clearly defined criteria was used some false positive tilt tests may also have biased the results. Furthermore our relatively low diagnostic yield of implantable loop recorder was probably due to a similar selection of patients, where the etiological diagnosis was the most difficult to establish and the rate of recurrent syncope was very low.

\section{Implications of unknown etiology}

The other major finding of the study was that only half of the patients discharged with the diagnosis of syncope received a definite etiological diagnosis despite workup and employment of numerous diagnostic tests. Important in this study is that the patients were selected according to the discharge diagnosis R55.9 leaving out patients who at discharge received other diagnoses. Some of these patients may already have been etiologically diagnosed, biasing these results towards a higher proportion of unknown etiology compared to other studies.

Previous smaller retrospective and prospective studies which did not use the ICD-10 discharge diagnosis have however reached similar results [1, 24, 26, 27]. Chen et al found that multiple potential causes of syncope are common and particularly in the elderly, the exact etiological diagnosis is hard to establish [28]. In our study the percentage of unknown etiology diminishes after workup but only by a decrease of $17 \%$ in absolute numbers. This may be caused by our case definition that the discharging physician after discharge or workup had to account for etiology and if not claimed in the chart the case was classified as unknown. We decided not to second-guess the evaluation of the clinicians. Also, importantly as previously stated, the discharge diagnosis R55.9 does not cover all cases of syncope. The R55.9 coding covers around $63 \%$ of the cases, thus a relatively large proportion receive other relevant diagnoses at discharge, which may bias our results towards even lower diagnostic yields. Furthermore we found no obvious age-dependent variation suggesting that the younger patients are easier to diagnose, but along with studies previously cited we found increasing prevalence of orthostatic and cardiac syncope in the elderly and more reflex syncope in the young.

It is therefore noteworthy that in the present study comparable rates of cardiovascular medication and comorbidities are seen in the group of undiagnosed patients (unexplained etiology) and in the group of cardiac etiologies. An extrapolation of these findings may indicate that a large proportion of patients in our study with unexplained syncope may have "covert" cardiac etiology and are at an increased risk of arrhythmogenic death. Further research is needed to clarify the implications of this finding, but it emphasizes the need to establish an etiological diagnosis.

\section{Limitations}

First, this is a retrospective study of hospitalized inpatient databases and must be weighted as such. A majority of syncope cases are treated in outpatient and general practice settings and generalizing our findings to outpatient or general practice databases should not be done. Therefore, data from those individuals who do not seek medical attention or who are only seen in outpatient clinic or offices are not captured. For syncope, this results in a slight bias to more severe cases of syncope because patients with milder/less severe symptoms may not seek medical attention.

Second our "gold standard" relied solely on chart documentation. However, when discharged from the hospital, patients tend to have more extensive workup. Therefore, the charts most likely reflected the "true diagnosis" but due to the retrospective observational character of this study no prespecified criteria was used for correct diagnosis of a given test and was left to the current practice of the department. Third, our case definition of syncope only included $63 \%$ of all patients with syncope according to our validation study, which essentially may bias the results towards higher proportions of unexplained syncope compared to other settings and syncope populations. Fourth, patients who at discharge could be classified as cardiac syncope and orthostatic hypo- 
tension syncope should not even have received the R55.9 discharge diagnosis but should have been given another concrete ICD-10 diagnosis (namely, I95.1, I45.x and I49.x, and so on) accompanied by R55.9 as a secondary diagnosis. Finally, we could not account for factors that might have influenced the attending physician in ordering certain tests or establishing the etiology of syncope.

\section{Conclusion}

In conclusion we found that the discharge diagnosis of R55.9 covers a wide variety of etiological manifestations, but mostly, it covers syncope due to unknown cause even after workup. The diagnostic yield of many tests implemented in the care path is generally low and more studies are needed for a better selection of patients.

\section{Acknowledgement}

Grants and funding sources, The Danish Heart Association, The Lundbeck Foundation, Snedkermester Sophus Jakobsens Fond, Arvid Nilssons Fond, Helsefonden and Knud Hoejgaards Fond.

\section{Conflict of Interest}

The authors have no conflict of interests related to the contents of this manuscript.

\section{References}

1. Sarasin FP, Louis-Simonet M, Carballo D, Slama S, Rajeswaran A, Metzger JT, Lovis C, et al. Prospective evaluation of patients with syncope: a population-based study. Am J Med. 2001;111(3):177-184.

2. Quinn J, McDermott D, Kramer N, Yeh C, Kohn MA, Stiell I, Wells G. Death after emergency department visits for syncope: how common and can it be predicted? Ann Emerg Med. 2008;51(5):585-590.

3. Ruwald MH, Hansen ML, Lamberts M, Hansen CM, Hojgaard MV, Kober L, Torp-Pedersen C, et al. The relation between age, sex, comorbidity, and pharmacotherapy and the risk of syncope: a Danish nationwide study. Europace. 2012;14(10):1506-1514.

4. Olde Nordkamp LR, van Dijk N, Ganzeboom KS, Reitsma JB, Luitse JS, Dekker LR, Shen WK, et al. Syncope prevalence in the ED compared to general practice and population: a strong selection process. Am J Emerg Med. 2009;27(3):271-279.

5. Ruwald MH, Ruwald AC, Jons C, Lamberts M, Hansen ML, Vinther M, Kober L, et al. Evaluation of the
CHADS2 risk score on short- and long-term all-cause and cardiovascular mortality after syncope. Clin Cardiol. 2013;36(5):262-268.

6. Soteriades ES, Evans JC, Larson MG, Chen MH, Chen L, Benjamin EJ, Levy D. Incidence and prognosis of syncope. N Engl J Med. 2002;347(12):878-885.

7. Alshekhlee A, Shen WK, Mackall J, Chelimsky TC. Incidence and mortality rates of syncope in the United States. Am J Med. 2009;122(2):181-188.

8. Getchell WS, Larsen GC, Morris CD, McAnulty JH. Epidemiology of syncope in hospitalized patients. J Gen Intern Med. 1999;14(11):677-687.

9. Kapoor WN, Hanusa BH. Is syncope a risk factor for poor outcomes? Comparison of patients with and without syncope. Am J Med. 1996;100(6):646-655.

10. Ruwald MH, Hansen ML, Lamberts M, Hansen CM, Vinther M, Kober L, Torp-Pedersen C, et al. Prognosis among healthy individuals discharged with a primary diagnosis of syncope. J Am Coll Cardiol. 2013;61(3):325-332.

11. Linzer M, Yang EH, Estes NA, 3rd, Wang P, Vorperian VR, Kapoor WN. Diagnosing syncope. Part 1: Value of history, physical examination, and electrocardiography. Clinical Efficacy Assessment Project of the American College of Physicians. Ann Intern Med. 1997;126(12):989-996.

12. Moya A, Sutton R, Ammirati F, Blanc JJ, Brignole M, Dahm JB, Deharo JC, et al. Guidelines for the diagnosis and management of syncope (version 2009). Eur Heart J. 2009;30(21):2631-2671.

13. Ruwald MH, Hansen ML, Lamberts M, Kristensen SL, Wissenberg M, Olsen AM, Christensen SB, et al. Accuracy of the ICD-10 discharge diagnosis for syncope. Europace. 2013;15(4):595-600.

14. Sun BC, Emond JA, Camargo CA, Jr. Direct medical costs of syncope-related hospitalizations in the United States. Am J Cardiol. 2005;95(5):668-671.

15. Colivicchi F, Ammirati F, Melina D, Guido V, Imperoli G, Santini M. Development and prospective validation of a risk stratification system for patients with syncope in the emergency department: the OESIL risk score. Eur Heart J. 2003;24(9):811-819.

16. Quinn J, McDermott D, Stiell I, Kohn M, Wells G. Prospective validation of the San Francisco Syncope Rule to predict patients with serious outcomes. Ann Emerg Med. 2006;47(5):448-454.

17. Del Rosso A, Ungar A, Maggi R, Giada F, Petix NR, De Santo T, Menozzi C, et al. Clinical predictors of cardiac syncope at initial evaluation in patients referred urgently to a general hospital: the EGSYS score. Heart. 2008;94(12):1620-1626.

18. Linzer M, Yang EH, Estes NA, 3rd, Wang P, Vorperian VR, Kapoor WN. Diagnosing syncope. Part 2: Unexplained syncope. Clinical Efficacy Assessment Project of the American College of Physicians. Ann Intern Med. 
1997;127(1):76-86.

19. Kapoor WN. Evaluation and outcome of patients with syncope. Medicine (Baltimore). 1990;69(3):160-175.

20. Baron-Esquivias G, Martinez-Alday J, Martin A, Moya A, Garcia-Civera R, Paz Lopez-Chicharro M, MartinMendez M, et al. Epidemiological characteristics and diagnostic approach in patients admitted to the emergency room for transient loss of consciousness: Group for Syncope Study in the Emergency Room (GESINUR) study. Europace. 2010;12(6):869-876.

21. Kouakam C, Vaksmann G, Pachy E, Lacroix D, Rey C, Kacet S. Long-term follow-up of children and adolescents with syncope; predictor of syncope recurrence. Eur Heart J. 2001;22(17):1618-1625.

22. Benbadis SR, Chichkova R. Psychogenic pseudosyncope: an underestimated and provable diagnosis. Epilepsy Behav. 2006;9(1):106-110.

23. Shen WK, Decker WW, Smars PA, Goyal DG, Walker AE, Hodge DO, Trusty JM, et al. Syncope Evaluation in the Emergency Department Study (SEEDS): a multidisciplinary approach to syncope management. Circulation.
2004;110(24):3636-3645.

24. Disertori M, Brignole M, Menozzi C, Raviele A, Rizzon P, Santini M, Proclemer A, et al. Management of patients with syncope referred urgently to general hospitals. Europace. 2003;5(3):283-291.

25. Youde J, Ruse C, Parker S, Fotherby M. A high diagnostic rate in older patients attending an integrated syncope clinic. J Am Geriatr Soc. 2000;48(7):783-787.

26. Ammirati F, Colivicchi F, Santini M. Diagnosing syncope in clinical practice. Implementation of a simplified diagnostic algorithm in a multicentre prospective trial the OESIL 2 study (Osservatorio Epidemiologico della Sincope nel Lazio). Eur Heart J. 2000;21(11):935-940.

27. Blanc JJ, L'Her C, Touiza A, Garo B, L'Her E, Mansourati J. Prospective evaluation and outcome of patients admitted for syncope over a 1 year period. Eur Heart J. 2002;23(10):815-820.

28. Chen LY, Gersh BJ, Hodge DO, Wieling W, Hammill SC, Shen WK. Prevalence and clinical outcomes of patients with multiple potential causes of syncope. Mayo Clin Proc. 2003;78(4):414-420. 